\title{
Service Design in Competitive Tendering of Bus Routes
}

\author{
Isam A. Kaysi \\ Ali S. Abbany \\ American University of Beirut
}

\begin{abstract}
$\overline{\text { Abstract }}$
Transit systems and buses, in particular, generally suffer from severe financial problems that affect their sustainability and levels of service. In an attempt to revive these systems, public authorities have recently moved toward more private sector participation, which could improve cost efficiency. This participation can take different forms depending on the roles of each sector in the provision and production of public transport. This article examines the different models for private sector participation in the provision of mass transit services, describing their respective benefits and disadvantages for both transit providers and users. Focus is, however, given to one specific strategy-competitive tendering - because of its successful application worldwide and its suitability to the case study context. Competitive tender structuring elements that relate to determining the size of the contract to be tendered as well as the allocation of routes among bid packages ("service design") is discussed in particular. A sound methodology for assessing bid packages of routes is developed and then applied for the case study of Beirut, Lebanon.
\end{abstract}

\section{Introduction}

Public transport systems and buses, in particular, represent the most efficient modes of transport in high-density urban areas. With their widespread 
networks, frequent service, reasonable fares, and capability of carrying large numbers of passengers, they theoretically best serve the three objectives of mobility, social equity, and congestion reduction. However, in many developing countries, these systems often suffer from considerable deficits, low quality of service, and unreliable operation (Yagi 1994). Great efforts are needed to revive those failing systems, and in many cities around the world, more private sector involvement appears to be the best way to achieve this.

In fact, many researchers consider that public organizations are less efficient, suffer from strong labor constraints, and lack sufficient initiative (Karlaftis 1998). They also view the private sector as being "more sensitive to economic incentives, more flexible and adoptive to changing market needs and structure, and more in tune with customer needs" (Karlaftis 1998).

Other researchers, however, claim that it is not the change in the operator itself that would possibly lead to cost savings and better operation, but the competition associated with the private sector's participation. Privatization, or even the threat of it, makes both public and private operators more competitive, pushing them to reduce their labor costs and improve their service levels (McCullough et al. 1998). A successful marriage of competition and regulation appears capable of substantially improving the efficiency and effectiveness of public transport systems.

Private sector participation can take different forms and strategies, each one having specific dimensions relating to provision and production of mass transit. In the following sections, the extent of and models for private sector participation are described and discussed.

\section{Organizational Models for Mass Transit}

The regulatory forms of mass transport services include, as suggested by Yagi and Mantell, public and private monopolies, deregulation, regulated competition, and competitive tendering strategies (Yagi 1994; Mantell 1993). Each of these models has advantages and disadvantages, and each might be suitable for specific environments based on political, economical, and social conditions. In the subsequent sections, these structures will be briefly introduced in terms of their respective benefits and disadvantages, and special attention will 
be given to the last option, which will be the one adopted in the illustrative case study.

\section{Public and Private Monopolies}

Public monopoly gives one public operator the exclusive rights for designing, owning, and operating all transit services. without any competition from other operators. This single operator could also be a privately owned company (in which case the setup is called "private monopoly") that works under regulatory rules set by the transit authority (Halcrow Fox 2000).

Theoretically, public monopoly enables the government to directly implement its accessibility and social equity concerns through the public operator. It creates a well-coordinated system that is able, with the government support, to expand its services without fear of financial risks (Yagi 1994). However, many countries cannot afford high subsidies, and without this financial support, such systems may not be able to return sufficient profits for the expansion and renewal of transit services (Transportation Research Board 2001).

As for private monopolies, they can provide consistency and coordination in the production of transit services, can benefit from possible economies of scale, and could eliminate the need for government subsidy. The main disadvantage is that monopolists tend to abuse the exclusive rights to maximize their revenues by increasing fares and providing lower quality services (Yagi 1994).

\section{Unregulated Systems}

Also called "open market" (Halcrow Fox 2000), an unregulated market presents no restrictions on transit operators, except those related to safety concerns, environmental issues, vehicle maintenance, and general business and traffic laws. Toward this end of organizational strategies, competition between different operators exists in the market, particularly to attract more riders and increase revenues. This competition benefits the whole mass transport system because it pushes operators to reduce costs, increase benefits, and accordingly invest in expanding and ameliorating services. Riders also benefit from lower fares (particularly in high-demand areas), a large variety of options, and possibly a more frequent operation (Salvucci et al. 1997). 
Deregulation, however, has many drawbacks and disadvantages. For instance, operators may suffer from "unfair competition, predatory practices and coercive or threatening tactics" (Salvucci et al. 1997). Riders also suffer because of the absence of any fare and service coordination, as well as respected schedules. Finally, with the preferred use of smaller vehicles at higher frequencies, congestion and environmental problems seem much more aggravated when adopting a similar strategy (Yagi 1994; Salvucci et al. 1997).

\section{Regulated Competition}

This system preserves the competitive aspect of deregulated markets, with additional rules regarding fares, level of service, entry to the system (through a license), and operated routes (Won 1995). These rules could enable the government to create an integrated network with sufficient coordination between different operators. Entry restrictions also set the stage for profitable services by eliminating destructive competition and benefit traffic conditions by limiting the number of transit operators and accordingly reducing congestion problems. The main disadvantages relate to possible preferential treatment that could be given by the regulator to stronger operators, need for continuous fare adjustments to maintain sufficient levels of profitability, and inability of the system, without public support, to maintain services in low demand areas (Salvucci et al. 1997; Mantell 1993).

\section{Competitive Tendering}

Competitive tendering (contracting out) falls midway between public or private monopolies and full deregulation techniques (Scurfield 1990). Baldwin and Cave defined it as "the allocation [by government agency] of a protected or exclusive right to exploit or carry out an activity such that consumers or the public gain an advantage-for example, an efficiently produced and competitively priced service" (Toner 2001). It enables the introduction of competition for the market, while keeping certain levels of public control over fares, service quality, and coordination between different operators.

Competitive tendering has been recently widely applied in many cities around the world, such as London, Copenhagen, and Stockholm. The experiences revealed many benefits in as far as cost savings, improved quality of ser- 
vice, network expansion, congestion reduction, amelioration in safety and environmental measures, and enhanced customer satisfaction (International Transit Studies Program 1998). In London, for example, 10 years after the initiation of the competitive tendering process, operating costs dropped by 47 percent due to lower labor costs and more efficient operation. Moreover, operated vehicle-kilometers expanded by 29 percent, and ridership levels increased by a very meaningful 5 percent (more than a 20\% drop in other areas of the UK) (Bayliss 1997). This success is, however, greatly dependent on a decisive and close monitoring of the performance of each operator. This would be best achieved when an authority that is completely independent from any political pressure (i.e., not the public operator) organizes the tender.

Competitive tendering requires a number of transport policies and legislative reforms to successfully achieve its objectives. Moreover, the transit authority needs to decide on two major aspects of the tendering process (Toner 2001):

- Who bears the revenue risk/what type of contract to adopt?

- How to design the contract?

\section{Type of Contract}

The adopted contract can be a cost, revenue, or shared contract. In cost contracts, the operator specifies in the bid the full cost required in exchange for provided services and which will be received irrespective of collected fares. Revenues are transferred to the transit authority that bears the revenue risks and is responsible for controlling the adherence of the contractor to the service levels cited in the contract (Scurfield 1990; Shaw 1996).

Revenue contracts, on the other hand, transfer revenue risks from the transit authority to the private operator, who keeps the collected fares. In some instances, the operator could receive additional subsidies in case the operated routes are nonprofitable; when the opposite is true, the operator might be asked to pay the transit authority for the "right to operate" (Scurfield 1990).

Shared contracts provide a compromise between cost and revenue contracts, whereby revenue risks are equally shared by the transit authority and private operator. This alternative is very beneficial because it creates incentives 
for both public and private parties to provide better service and become more cost efficient (Mantell 1993).

Selecting the appropriate contract form for a specific case is not an easy task. In fact, although revenue contracts transfer all revenue risks from the public authority to the private operator, cost contracts could be more appropriate when other criteria such as competition, incurred cost, incentives, and ease of contract management are looked at (Shaw 1996). The selection should follow: a careful and detailed study of existing conditions as well as aims and capabilities of the transit authority.

\section{Competitive Tender Structuring}

In every contract or competitive tender, the following issues should be clearly specified (Halcrow Fox 2000; Wallis and Bray 2001):

- routes to be tendered;

- contract size;

- contract duration and renewal;

- fares;

- schedules;

- vehicle characteristics;

- service and safety standards;

- asset ownership and use;

- roles and responsibilities of both the regulating authority and private sector;

- amount of control the regulating authority has over the product; and

- system integration policies (e.g., service coordination, integrated fares and ticketing, passenger information).

Covering all the above aspects of the competitive tender falls beyond the scope of this article. The work described in this article focuses on service design, which will be further discussed in the next section.

\section{Service Design}

Service design involves competitive tender structuring elements that relate to determining the size of the contract to be tendered as well as the allocation of 
routes among bid packages. "The size of the contract package is critical" (Gwilliam 1997). In the bus industry, the minimum package size is the single route but could expand to cover a whole area. For a specific system, it would be beneficial to award enough contracts to avoid reliance on a single provider and encourage losers to bid again (Mantell 1993). Small contracts also give more chance to smaller companies to participate in the bidding process. With fewer routes in the package, the required financial and technical resources could be arailable for a larger number of companies, leading to more competition in the bids. In London, for example. the network was first contracted out on a route-byroute basis. with the possibility of joint bids for a number of routes. The selection of single routes that were prioritized in the tendering process was based on (World Bank 1999):

- poor financial performance,

- poor operational performance,

- likelihood of attracting competition,

- resources needed, and

- location.

A larger system would, however, allow the operator to benefit from economies of scale and cross-subsidies, as well as the possibility to allocate resources as per peak-hour demand (World Bank 1999). Moreover, it enables the operator to provide a more integrated and coordinated service within the package. However, the package size should not exceed an upper limit that could be characterized as that beyond which fewer than three competitors are confidently capable of participating in the bid (Halcrow Fox 2000).

In areas where capabilities of different operators are limited, a good practice would be to start by contracting out small packages that attract a wide range of operators, and then move toward larger contracts following the growth in the power of different competitors (Halcrow Fox 2000). A similar approach was adopted in London where small suburban routes were the first to be opened for tender, before larger areas were gradually introduced in the bidding process. 
Finally, one interesting approach for the selection of tendered routes was adopted in Uzbekistan. The first routes to be put in tender were those served by many private operators and showing a certain degree of competition. The philosophy behind this approach is that more operators would be interested in obtaining exclusive rights to work on these profitable routes in order to increase their revenues. The on-the-street competition will thus be transferred to the tendering process, leading to a decrease in the bid prices (Gwilliam et al. 2000).

\section{Proposed Framework for Service Design in Competitive Tendering}

The research efforts described above have considered competitive tendering and its applications in different cities around the world. However, they all focused on the historical background and the implications of this organizational form and only marginally discussed the service design step of grouping bus routes into bid packages. The article addresses this aspect. It proposes a flexible framework for service design that consists of:

1. generating routes (i.e., network design),

2. defining a basis for route packaging, and

3. evaluating obtained packages based on assessment criteria that reflect system objectives.

The article's objective is not to cover all aspects of competitive tendering. but simply to propose a systematic approach for grouping routes into contract packages.

\section{Generation of Routes}

The generation of routes when a bus network is put out for tender may differ from procedures commonly adopted for network design and which are aimed basically at single monopolist operators. The bus network may need to be completely redesigned to best serve the contracting out process. However, this aspect is beyond the scope of this article and could constitute the basis for interesting further research. 


\section{Basis for Route Packaging}

The second step in the framework involves investigating ways of grouping routes together based on a common feature. In fact, depending on the geometry of the network, routes could be combined into packages according to several considerations. Two such attributes are: the common terminal or the served corridor. In the first approach. all those routes that have a common terminal, or relatively close terminals, would be sorted together and tendered as one package to be operated by a single company. This strategy enables the operator to consolidate all of its fleet in one garage at or close to the terminal, thus reducing the lost time spent in moving vehicles between the garage and the terminal. It is also beneficial for the operation within the terminal, which becomes more coordinated, having only one major contractor on the ground. The main disadvantage is that all service contractors could potentially operate anywhere in the city, and there is no protected area for each one of them. There might also be long overlaps between routes of different packages, making the system a rather complicated one for both the mass transit authority and users.

In the second approach, all routes that fall within a major corridor are combined in one contract and served by a single operator. In this case, there will be a clearer definition of relatively independent and nonoverlapping service areas, and the contractor would focus on a certain patronage within the boundaries of its franchise. Moreover, service in the area would be better coordinated, having a single operator in charge. A major disadvantage is that every operator may need to use many stations and will suffer from additional costs when moving the fleet from the garage to the terminal, and vice versa. In addition, at each terminal there will be more than one service contractor, and the service at the station might become hard to organize and coordinate. In cases where the transit authority is not capable of successfully managing shared stations, the drawbacks resulting from the complexity of operations may outweigh the benefits of joint station operations whereby transfers and fare integration could be more easily achieved with contractors operating in common terminals.

\section{Assessment of Bid Packages}

The third step in the proposed framework comprises the assessment of the obtained tender packages to ensure their consistency with the objectives of the 
tendering process. Within this task, the different packages need to be appraised based on a number of parameters to determine which methodology best serves the objective of increasing the competitive aspect of the tendering process. Three criteria that may be adopted for such assessment are:

1. required fleet size for tender package,

2. degree of overlap between tender packages, and

3. balance between profitable and noncommercial routes in a tender package.

The required fleet size typically depends on the one-way route lengths in the different packages, average running speeds, and average headways. The fleet size determines the financial capabilities of the private companies that could participate in the tender, since larger fleet requirements typically prevent small operators from bidding for the service. It is, therefore, necessary to generate fleet requirements that permit operators with the widest range of resources to enter the bid.

The degree of overlap is a controversial criterion. On one hand, minimum overlap is required to ensure relatively independent operation, while on the other hand, more overlap could reflect a better connectivity and more competition in the network. Finally, each contract should, as much as possible, balance profitable and losing routes such that each will end up generating revenues (if possible), in the interest of both the contractors and the transit authority. This last criterion relates more closely to revenue contracts whereby individual operators are fully responsible for the financial performance of their package.

It is understood that the decision on whether to go with competitive tendering or not and the subsequent selection of tender packages is typically undertaken by local transit boards. The boards might need to reorganize the whole mass transit system, and regulate the operation of other road transport operators such as minivans, jitneys, and taxis. The presented approach to route packaging and the corresponding assessment criteria are only prototypical and may be modified depending on the objectives of the transit authority. Accordingly, this article proposes a simple example of the technical analysis 
that may be undertaken to assist transit authorities in subdividing their network for competitive tendering of bus operations. The above described evaluation matrix is presented in Table 1.

\begin{tabular}{|c|c|c|c|c|}
\hline & & Eval & $\begin{array}{l}\text { ble } 1 \\
\text { ion Mat }\end{array}$ & \\
\hline 0 & & & & ent Criteria \\
\hline ț & & $\begin{array}{l}\text { Required } \\
\text { Fleet Size }\end{array}$ & $\begin{array}{l}\text { Degree of } \\
\text { Overlaps }\end{array}$ & $\begin{array}{c}\text { Balance Between Profitable and } \\
\text { Noncommercial Lines }\end{array}$ \\
\hline. & By teminal & & & \\
\hline 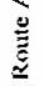 & By corridor & & & \\
\hline
\end{tabular}

\section{Case Study: Application to Beirut}

Tendering the public bus network in Lebanon is a major component of the reform plan proposed by the Lebanese Ministry of Transport (MOT) to organize the land transport sector in the country. With this plan, the MOT aims at reducing the serious lack of organization that characterizes the Lebanese public transit sector, as well as minimizing the financial burden of its operation. The scope of the study covers the whole country, but priority is given to major cities such as Beirut, which is the focus of the following sections (World Bank 1999; Baaj 1999).

\section{Current Public Transport Sector in Beirut}

The mass transit system in the Greater Beirut Area (GBA) currently operates under complete deregulation. Five different types of mass transit operators compete to serve the limited patronage, which accounts for only 32 percent of the daily motorized trips (Baaj 1999). These are the publicly owned Railway and Public Transport Authority (RPTA), the privately owned Lebanese Commuting Company (LCC), private minibuses, jitneys, and taxis. These operators provide a total capacity that exceeds the current demand, which dangerously reduces their revenues, and leads to a serious drop in the levels of service. In fact, within GBA, RPTA, and LCC 164 and 185 buses, respectively, operate and these share the roads with 2,000 minivans and 25,000 jitneys and taxis. 
This large number of transit vehicles operates alongside private passenger cars to create major congestion problems in the city. Moreover, the quality of bus service is extremely low, given the poor vehicle maintenance, aggressive driving patterns that aim at capturing more riders, and absence of a fixed operating schedule. As a result, costs to the economy are substantial because of the increased trip times, transport costs, gasoline consumption, and pollution levels. In addition, the bus authority suffers from high annual subsidies that reached 20.5 billion L.L ( $\$ 13.7$ million) in year 2000, that is a subsidy of 1,400 L.L ( $\$ 0.93$ ) for every passenger trip, or three times the collected fare (Baaj 1999).

With all these difficulties, a reform plan seems vital for the preservation of mass transit services in Beirut. The privatization of bus operations under privileged contracts appears the most appropriate option, as it has proven to entail efficiency in other cities worldwide, and because the private sector has shown remarkable capabilities in running a profitable business despite all the complexity of the Lebanese transit sector. In fact, looking back at the performance of RPTA and LCC by the end of 1998, the latter agency generated 28 percent higher revenues, and its cost per bus-km was less than half that of the public company. The two companies operate over the same number of daily hours (12 hours) and collect the same fare (500 L.L or $\$ 0.33$ per trip) but differ in the operated routes-RPTA runs 27 lines (some of which are not profitable but should be operated because of social concerns) while LCC runs 11 lines (all of which are profitable). Moreover, RPTA owns old and poorly maintained large buses, while LCC works with newer medium-size buses that enable the adoption of shorter headways and accordingly result in higher vehicle-km figures (Baaj 1999). To all this one may add the flexibility of LCC in recruiting the appropriate number of staff, free from political and labor union pressures that exist with RPTA. As a result, LCC has performed much better than RPTA, and private companies in general are expected to perform better than the public agency, mainly due to the strong political interventions that inhibit the successful operation of public corporations in Lebanon. Table 2 summarizes the financial performance of both companies in 1998 . 


\begin{tabular}{|l|l|l|}
\hline \multicolumn{3}{|c|}{ Table 2} \\
\hline \multicolumn{2}{|c|}{ Performance of RPTA and LCC in 1998} \\
\hline Fleet size in operation & $R P T A$ & $L C C$ \\
Routes in operation & 164 buses & 185 buses \\
Yearly ridership & $25 *$ & $12 *$ \\
Yearly travel distance & 14 million & 18 million \\
Yearly revenues & 10.5 million bus-km & 12.8 million bus-km \\
Yearly costs & 7 billion L.L & 9 billion L.L \\
Costbus-km & 20.5 billion L.L & 11.6 billion L.L \\
Ratio of employees to operational fleet size & 3.8 employees per bus & 2.4 employees per bus \\
\hline * RPTA has currently added two routes and LCC recently merged two of its routes into a single one. \\
\hline
\end{tabular}

\section{Current Bus Network}

Currently, RPTA operates 27 lines in GBA and suburbs, 6 of which are equally served by LCC, which in turn operates a total of 11 lines. At this stage of the research described in this article, the proposed framework was applied to the currently operating routes, without redesigning the whole network in a way that would better serve the contracting out process. Accordingly, the application of the first step in the framework to the Beirut case study simply meant considering the existing routes. These include 32 lines (see Figure 1).

The network can be defined as a radial one, with major peripheral routes within Beirut. The origin of the lines is not the same, but the trend is that many routes radiate from Beirut toward the suburbs around the city. Areas served by the bus network extend to the north, south, and east, reaching cities such as Jbeil, Broumana, and Aley. There are 13 lines that extend beyond the limits of municipal Beirut, 12 lines that connect the city of Beirut with the nearest southern and northern suburbs, while the remaining 7 lines operate within the limits of the city, with some moving in an east-west direction, and others moving in the north-south direction. 


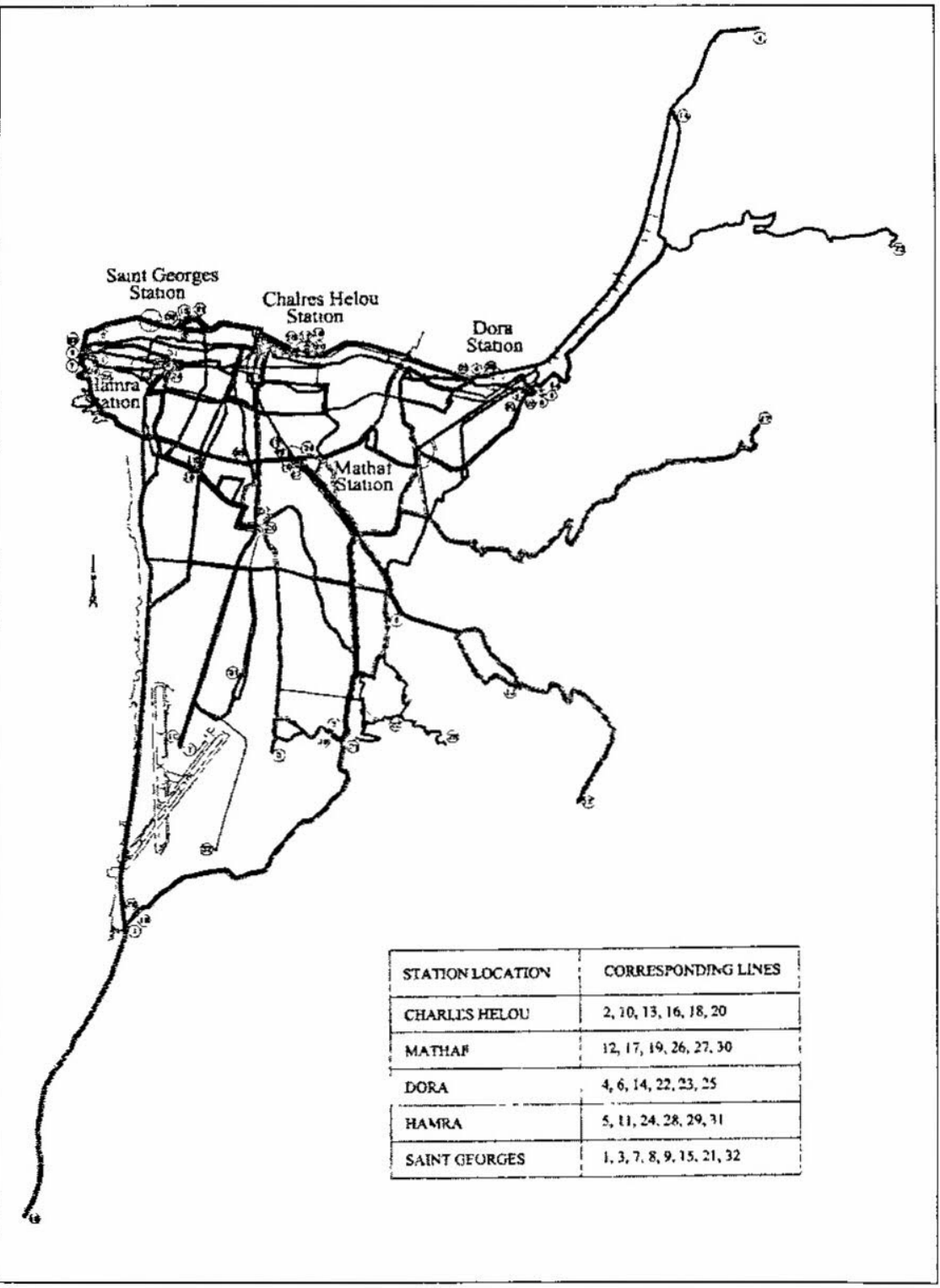

Figure 2. Subdivision by terminal 


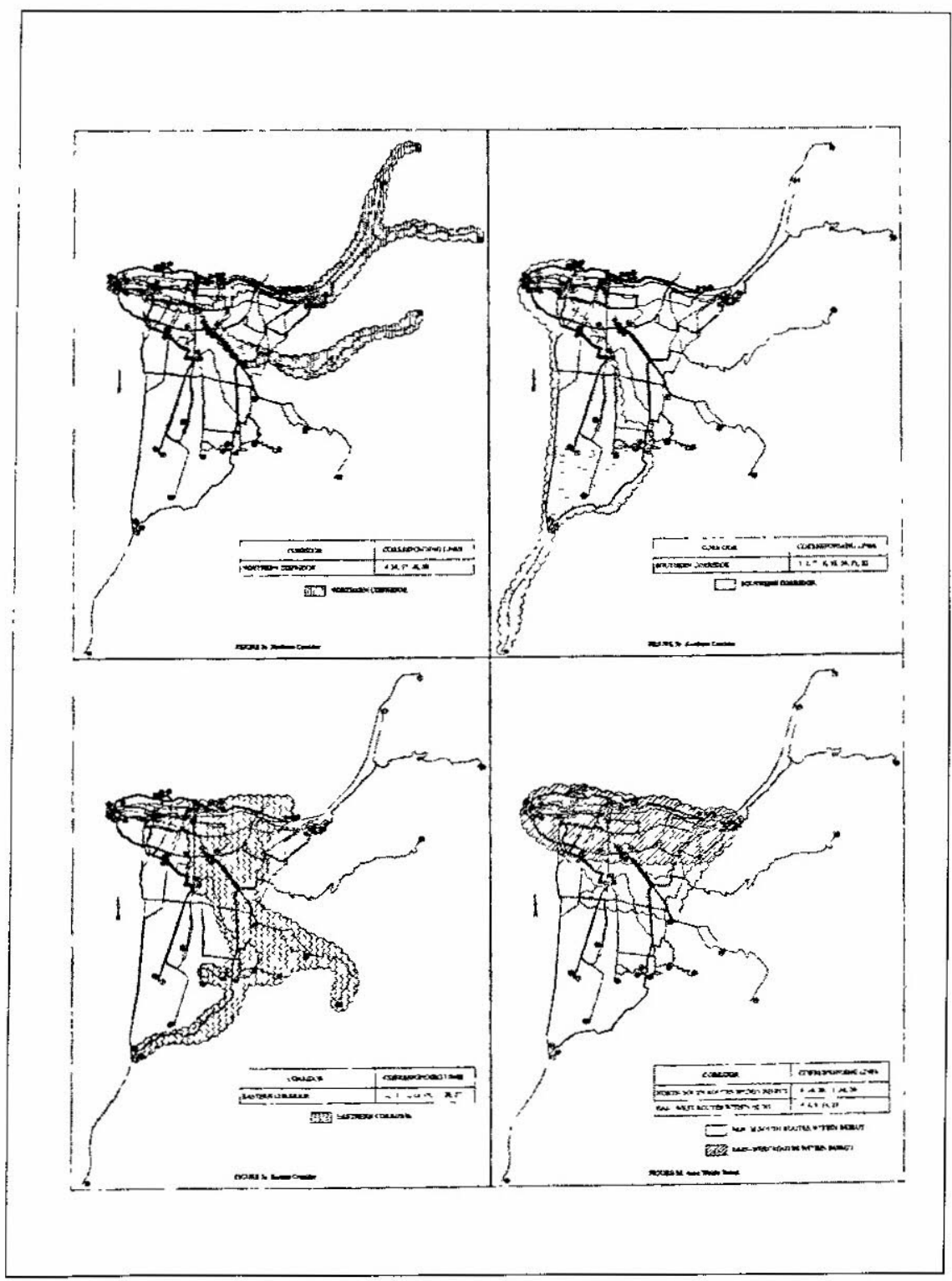

Figure 3. Subdivision by corridor 
No reliable records exist at the transit authority regarding average speeds and headways for different routes in the network. For this reason, data collected by engineering students from the American University of Beirut were used to approximate those values. Based on point checks and ride checks of LCC routes conducted by the students, operating speeds and headways on several bus routes were estimated. Obtained speed values ranged from 10 to $20 \mathrm{~km} / \mathrm{hr}$ and headways varied between 7 and 15 minutes. As for the other routes where no information was available, judgment was used to approximate possible speed and headway values. Clearly, more detailed surveys and data collection would be required in a more comprehensive study, but as far as this article is concerned, the values obtained were considered appropriate for demonstrating the applicability of the proposed framework.

In each package, fleet sizes of the corresponding routes were added up to roughly estimate the minimum resources that should be provided by the contractor. Four of the groups in the "terminal" approach had close fleet requirements ranging from 47 to 69 buses. Only the fifth group, which also had the longest network, required 80 buses. As for the first, third, fourth, and fifth contracts of the "corridor" approach, the required fleets were extremely close, ranging from 55 to 59 buses. The second contract, however, necessitates the use of 80 buses. If the routes within Beirut were combined. their fleet size would double to exceed 110 buses, diverging by far from the other contracts. All required fleets in both approaches are relatively large, possibly restraining small contractors from participating in the tender. Finally, if we were to consider only this criterion, allocating routes by corridor would better serve the equity concern.

Degree of Overlap. Overlaying the different packages allowed the identification of portions of routes shared by two or more packages. This indicated that, when the first approach was used, many areas of overlap exist among all the contractors, and they practically exist everywhere within the city. Four major areas of overlap may be identified, with route lengths exceeding $6 \mathrm{~km}$ each. The total length of route overlap is significant, accounting for $55.6 \mathrm{~km}$. or 15.2 percent of the total network length. 
In the second approach, the length of overlap is significantly reduced, accounting for a mere 9.6 percent of the total network $(35.1 \mathrm{~km})$, with the longest overlap not exceeding $7 \mathrm{~km}$. In this system, it appears that the three radial corridors are almost independent from each other, and the main overlaps exist with the routes within Beirut. Furthermore, if the lines within Beirut are combined, the overlaps will be further reduced since most of them occur within the boundaries of the city. Although interlining of routes might be beneficial for passengers in that it allows for competition to exist directly on the road. the objective of this assessment criterion within the Beirut case study would be to minimize overlaps between various packages. This decision was adopted in order to move away from the current situation of the deregulated bus system of Beirut, whereby the prevailing on-the-road competition has led to aggressive driving patterns that endanger pedestrian and vehicle movements, and that cause daily and costly accidents. Clearly, the network generated from the "corridor" methodology better serves our objective of minimizing the degree of overlap without completely eliminating it, thus maintaining possibilities for connectivity and transfer.

Package Profitability. The most crucial aspect of the contracting out strategy relates to the balance of profitable and noncommercial routes existing within each package. To perform an effective study, accurate and stable data on the financial performance of each line are essential. However, with the simple objective of demonstrating the application of the proposed framework, this analysis was conducted based on data available from limited surveys as well as personal knowledge of the operating environment in Beirut.

Surveys conducted recently were useful in determining approximate values of the number of passengers carried per trip on different bus routes. Clearly, these values need to be revised to accommodate daily and seasonal variations. For the routes surveyed, average passenger loads varied between 19 and 60 passengers per bus trip.

Revenue figures were generated from available ridership data and were translated into revenues per bus-km. Results ranged from 900 L.L ( $\$ 0.6) /$ bus$\mathrm{km}$ to $1,900 \mathrm{~L} . \mathrm{L}(\$ 1.3) / \mathrm{bus}-\mathrm{km}$. These figures are applicable to LCC routes, 
and in the absence of accurate data, existing routes were accordingly divided into three categories:

1. profitable routes with average revenues of $1250 \mathrm{~L} . \mathrm{L}$ ( $(\mathrm{S} 0.83) / \mathrm{bus}-\mathrm{km}$ :

2. marginal routes with average revenues of $900 \mathrm{~L} . \mathrm{L}$ ( $\$ 0.6) / \mathrm{bus}-\mathrm{km}$; and

3. noncommercial routes with average revenues of 600 L.L (S0.4)/bus$\mathrm{km}$.

Identifying the revenue level of each route given this categorization was achieved based on personal judgment, performance measures developed in previous studies, and the assumption that all routes currently operated by both companies are profitable by default. For instance, routes serving densely populated areas with low-income levels were considered profitable. This assumption is supported by the relatively high cost-recovery measures previously characterizing such lines. Other lines that in the past had average cost recovery were characterized as being marginal. Finally, noncommercial routes were those serving either less populated regions or high-income residential blocks (Bassil 1993; Kaysi and Bassil 1995).

As for the cost, given that LCC and RPTA had average costs of 920 L.L/bus-km and 2,000 L.L/bus-km in 1998 (Table 2), an average cost of 1,000 L.L (\$0.7)/bus-km was attributed to all the lines, assuming that private sector companies would achieve cost figures comparable to those of LCC.

Next, net revenues of routes in every package are summed to estimate their financial profitability. For packages in the first approach, profitability levels were not consistent, with two losing packages and three profitable ones. With this approach, there is a high need for cross-subsidy between different packages, and the subsidy will be essentially taken from the highly profitable Hamra package. As for the packages in the second approach, their net revenues seem more consistent with two contractors making a moderate return, two contractors achieving a higher net revenue, and only one group losing, but at a limited rate. This last approach seems to better serve the equity concern, especially that no package is losing or profiting excessively. Table 3 summarizes the results of the complete package assessment. 


\begin{tabular}{|c|c|c|c|c|}
\hline \multicolumn{5}{|c|}{$\begin{array}{c}\text { Table } 3 \\
\text { Evaluation Matrix }\end{array}$} \\
\hline & & $\begin{array}{l}\text { Required } \\
\text { Fleet }\end{array}$ & $\begin{array}{l}\text { Degree of } \\
\text { Overlap }\end{array}$ & $\begin{array}{l}\text { Net Revenues } \\
\text { (L.L./ } / \text { bus-km) }\end{array}$ \\
\hline \multirow{5}{*}{$\begin{array}{l}\text { Allocation } \\
\text { by Endpoint }\end{array}$} & Charles Helou & 51 & \multirow{5}{*}{$\begin{array}{l}55.6 \mathrm{~km} \\
(15.2 \%)\end{array}$} & -200 \\
\hline & Mathaf & 61 & & 540 \\
\hline & Dora & 47 & & -555 \\
\hline & Hamra & 69 & & 3260 \\
\hline & Saint Georges & 80 & & 361 \\
\hline \multirow{5}{*}{$\begin{array}{l}\text { Allocation } \\
\text { by Corridor }\end{array}$} & Northern Corridor & 59 & \multirow{5}{*}{$\begin{array}{l}35.1 \mathrm{~km} \\
(9.6 \%)\end{array}$} & 650 \\
\hline & Southern Corridor & 80 & & 1031 \\
\hline & Eastern Corridor & 59 & & -430 \\
\hline & N-S Routes Within Beirut & 55 & & 630 \\
\hline & E-W Routes Within Beirut & 55 & & 1525 \\
\hline
\end{tabular}

\section{Conclusions and Further Research}

This article addressed the issue of privatization of mass transit systems. Several approaches were discussed, including public and private monopolies, deregulation, regulated competition, and contracting out strategies. More focus was given to this last arrangement, and a brief description of the contract format was also specified.

Based on international experience in competitive tendering, a flexible framework for allocating bus routes into tendered packages was defined and applied to the city of Beirut. The methodology consisted of grouping routes either by a common terminal or by the shared corridor they serve. The obtained packages were then assessed based on three criteria relating to fleet size, degree of overlap, and financial profitability. This assessment task should lead to a preliminary conclusion as to the preferred basis for route packaging based 
on the evaluation criteria. In the case study, the second methodology is recommended because it best served the defined objectives.

Several assumptions and simplifications were undertaken to complete the case study application of the proposed framework. For instance, no network design was performed, and the proposed framework was applied to already existing routes. It is, however, possible to devise different network design procedures that best suit the packaging context, and this could form the basis of additional research in the field. Moreover, while the available data were not very accurate, they demonstrated application of the proposed framework. More work is required in data collection and validation, especially as far as ridership and financial information are concerned. Finally, the assessment criteria applied to the case study are only prototypical, and modifications could be introduced to the evaluation matrix depending on the specific transit systems components and objectives. For instance, issues of fare integration and transfers, which were not addressed in this article, could also be included in the evaluation matrix.

\section{References}

Baaj, M. 1999. A plan for the reform and organization of the land public transport sector in Lebanon. Plan prepared by the Lebanese Ministry of Transport.

Bassil, G. 1993. Bus public transit in Beirut: A study of system characteristics and potential. Thesis. American University of Beirut.

Bayliss, D. 1997. Bus privatization in Great Britain. Proceedings of the Institution of Civil Engineers-Transport, pp. 81-93.

Gwilliam, K. M. 1997. Contract design for concessions and franchises. The World Bank.

Gwilliam, K. M., R. T. Meakin, and A. Kumar. 2000. Designing competition in urban bus passenger transport: Lessons from Uzbekistan. Transportation. Water and Urban Development Department, The World Bank, Transport No. UT-41, Discussion Paper. 
Halcrow Fox. 2000. Review of urban public transport competition. Draft final report. Department for International Development.

International Transit Studies Program. 1998. Public-private partnerships and innorative transit technologies in Scandinavia. Transit Cooperative Research Program.

Karlaftis, M. G., J. S. Wasson. and E. E. Steadham. 1998. Impacts of privati-ation on the performance of urban transit systems. Paper presented at the annual meeting of the Transportation Research Board.

Kaysi, I., and G. Bassil. 1995. Incremental bus allocation with competing mass transit services. Transportation Research Record 1496. Transportation Research Board, National Research Council, Washington, DC, pp. 68-74.

Mantell, N. 1993. Alternative strategies for private sector participation in urban mass transit. M.S.T. Thesis. Massachusetts Institute of Technology, Cambridge.

MicCullough, W. S., B. D. Taylor, and M. Wachs. 1998. Transit service contracting and cost efficiency. Transportation Research Record 1618, Transportation Research Board, National Research Council, Washington, DC, pp. 69-77.

Salvucci, F., N. Wilson, and S. Yagi. 1997. Organizational options for public transport: A critical appraisal of experience to date and prospects for the future in North America. 5th International Conference on Competition and Ownership in Surface Passenger Transport.

Scurfield, R. G. 1990. Competitive tendering for public bus services. Transportation, Water and Urban Development Department, The World Bank, Transport No. UT-1.

Shaw, N. 1996. Bus franchises: Should gross or net contracts be preferred? Transportation, Water and Urban Development Department, The World Bank, Transport No. UT-7.

Toner, J. P. 2001. The London bus tendering regime-principles and practice. 7 th International Conference on Competition and Ownership in Surface Passenger Transport, Molde. 
Transportation Research Board, Committee for a Study of Contracting Out Transit Services. 2001. Contracting for bus and demand responsive transit services: A survey of U.S. practice and experience. Transportation Research Board, National Research Council, Washington, DC, Special Report 258.

Wallis, I., and D. Bray. 2001. Competitive tendering for bus services: The improved Adelaide model. 7th International Conference on Competition and Ownership in Surface Passenger Transport, Molde.

Won, J. 1995. Assessment of alternative structures for privately operated bus systems. Transportation Research Record 1503, Transportation Research Board, National Research Council, Washington, DC, pp. 23-28.

World Bank. 1999. Options for reforming public transport service. Final report submitted to the Ministry of Transport, Republic of Lebanon.

Yagi, S. 1994. Alternative strategies for public transport improvement in developing countries: A case study of Beirut. M.S.T. Thesis. Massachusetts Institute of Technology, Cambridge.

\section{About the Authors}

ISAM A. KAYSI (isam@aub.edu.lb) is an associate professor of civil and environmental engineering at the American University of Beirut. He received his Ph.D. in transportation systems and an M.S. degree from the Massachusetts Institute of Technology. Prior to joining the AUB faculty, he worked as a consultant at Multisystems, Inc., in Cambridge, Massachusetts. His areas of research include behavioral response, modeling, and evaluation of Advanced Traveler Information Systems; application of dynamic assignment-simulation methodology to evaluate traffic management strategies; urban mass transit planning, transit systems evaluation, and modeling of transit market arrangement implications; and feasibility assessment and project delivery considerations in infrastructure planning.

ALI S. AbBany (ali.abbany@darbeirut.com) received his bachelor's degree in civil engineering in from AUB, and is presently pursuing a master's degree in civil engineering, major transportation at the university. 
Mr. Abbany's research topic covers the process of competitive tendering of bus routes, with special focus on the methodologies for designing bid packages of routes, and on the possible implications of this process on transit network design. Mr. Abbany is also a project engineer with Dar Al-Handasah Consultants-Shair \& Partners. He has considerable experience airport design, having worked on the Dubai International Airport sExpansion project and New Doha International Airport master plan. He has also practiced traffic modeling techniques by conducting the traffic analysis for the Beirut Peripherique Highway using EMME/2. 
